\title{
Emergency Contraception Provision: A Survey of Michigan Physicians from Five Medical Specialties
}

\author{
XIAO XU, Ph.D., ${ }^{1}$ ANJEL VAHRATIAN, Ph.D., ${ }^{1}$ DIVYA A. PATEL, Ph.D. ${ }^{1}$ \\ ANNIE-LAURIE McREE, M.P.H., ${ }^{2}$ and SCOTT B. RANSOM, D.O., M.B.A., M.P.H. ${ }^{1}$
}

\begin{abstract}
Objective: Despite the controversy over expanding delivery options for emergency contraceptive pills (ECP), little is known about physicians' attitudes toward over-the-counter (OTC) provision of ECP, and prior research on physicians' practices often has focused on a single specialty. This study examined the attitudes and practices regarding advance provision and OTC status of ECP among physicians in five medical specialties likely to encounter patients in need of ECP.

Methods: A mail survey of a random sample of 850 Michigan physicians in family/general medicine, internal medicine, obstetrics/gynecology, pediatrics, and emergency medicine was conducted. Respondents' ECP-related attitudes and practices were assessed, and differences by physician characteristics were examined using chi-square tests and multivariable logistic regression analyses.

Results: Two hundred seventy-one physicians responded to the survey (response rate $=$ $32 \%$ ), with $42 \%$ of them favoring OTC provision of ECP and $40 \%$ opposing it. Half of respondents never routinely initiated discussions about ECP with their sexually active, female patients, and $77 \%$ of respondents did not routinely offer advance prescriptions. After adjusting for other factors, including medical specialty, older physicians ( $\geq 50$ years) were significantly more likely than their younger counterparts to support OTC provision of ECP (OR = $2.9,95 \%$ CI 1.7-4.9) or offer advance prescriptions (OR $=2.5,95 \%$ CI 1.1-5.8). Physicians with a specialty in obstetrics/gynecology were 3.5 times (95\% CI 1.3-9.8) as likely as physicians in family/general medicine to offer advance prescriptions for ECP, and female physicians were 2.5 (95\% CI 1.05-6.0) times as likely as male physicians to offer advance prescriptions. Graduation from a medical school within the United States and practicing in a private practice were marginally associated with a lower likelihood of supporting OTC status of ECP (OR = 0.5, 95\% CI: 0.2-1.0; and OR $=0.6,95 \%$ CI 0.3-1.1, respectively).

Conclusions: Certain physician characteristics were significantly associated with their ECPrelated attitudes and practices. The majority of physicians surveyed in this study did not offer advance prescriptions for ECP, and few had initiated discussions on ECP with patients, which may pose critical barriers to patients' timely access.
\end{abstract}

\footnotetext{
${ }^{1}$ Department of Obstetrics and Gynecology, University of Michigan, Ann Arbor, Michigan.

${ }^{2}$ Department of Health Behavior and Health Education, School of Public Health, University of Michigan, Ann Arbor, Michigan.

Financial support for this study was provided by the Institute for Research on Women and Gender at University of Michigan. X.X. and S.B.R. were partly supported by the National Institutes of Health Roadmap Initiative grant 1 P20 RR020682-01. A.V. was supported by the Building Interdisciplinary Research Careers in Women's Health (BIRCWH) program, National Institutes of Health (1 K12 HDO1438).
} 


\section{INTRODUCTION}

$\mathbf{E}$ MERGENCY CONTRACEPTIVE PILLS (ECP) are both safe and effective in reducing the risk of pregnancy after unprotected sexual intercourse or contraceptive failure and may be responsible for up to $43 \%$ of the decline in abortions in the United States between 1994 and 2000. ${ }^{1-3}$ ECP can be effective if taken up to 120 hours after unprotected intercourse or contraceptive failure; however, its efficacy decreases with prolonged time to initiation. ${ }^{2}$ Even though it has been announced by the U.S. Food and Drug Administration (FDA) as safe and effective since 1997,4 ECP remains an underused method of pregnancy prevention. ${ }^{5}$

To increase availability of ECP, prior studies have examined several dispensing options, including direct access through pharmacists, ${ }^{6-8}$ provision of a prescription by providers in advance of need (i.e., advance provision), ${ }^{9-13}$ and direct access to ECP without a prescription by making it available over-the-counter (OTC). ${ }^{14,15}$ The studies provide evidence that these dispensing options are effective in increasing the use of ECP.

On August 24, 2006, Plan B ${ }^{\circledR}$ (Barr Pharmaceuticals, Inc., Pomona, NY) - the only dedicated ECP product currently in the United States-was approved by the FDA for nonprescription sales to women and men $\geq 18$ years in the United States. ${ }^{16}$ Prior to this recent FDA ruling, pharmacy access and advance provision were the two dispensing methods available in the United States. Only nine states allowed access to ECP directly through a pharmacist under certain conditions, and several states had adopted restrictions on ECP provision (e.g., allowing pharmacists the option to refuse to dispense contraceptives). ${ }^{17}$ For the majority of the women, advance provision from a physician has been the only option to obtain ECP. Although Plan $B^{\circledR}$ available without prescription in pharmacies, advance provision remains the main dispensing method for women under the age of 18, and physicians still play a critical role in notifying and educating women (regardless of age) about the availability and efficacy of ECP. Therefore, a better understanding of physician attitudes and dispensing practices surrounding ECP could inform interventions designed to facilitate access.

Most prior research on this issue has focused on a single specialty, such as emergency medicine $^{18-20}$ or obstetrics/gynecology, ${ }^{21}$ even though women routinely access healthcare from physicians in a wide variety of specialties. ${ }^{22}$ This study was conceptualized and conducted prior to the recent FDA approval of nonprescription use of Plan $\mathrm{B}^{\circledR}$ and presented a unique opportunity to examine physicians' attitudes and practices about ECP immediately before the change in dispensing method. The objective of the present study was to examine physicians' attitudes toward the OTC status of ECP, their practice of advance provision of $\mathrm{ECP}$, and important factors that were associated with these ECP-related attitudes and practices. By assessing physicians' daily practices surrounding ECP, our data identified several aspects of care (e.g., patient-provider communication) that need to be improved. These findings will largely inform future intervention efforts in promoting women's timely access to ECP.

\section{MATERIALS AND METHODS}

\section{Survey}

In 2005, we conducted a mail survey of a random sample of Michigan physicians to assess their attitudes and practices regarding ECP provision. As of November 2004, there were a total of 29,906 physicians licensed in Michigan who were actively engaged in the practice of medicine or in a closely related activity, such as medical research/teaching. ${ }^{23}$ The Michigan State Medical Society (MSMS) has a membership of 14,000 physicians with characteristics similar to the overall Michigan physician population in the areas of demographics, specialties, education, Medicaid and Medicare participation rate, and use of technology in the physician office. ${ }^{24-27}$ A mailing list of 3,756 MSMS member physicians with a specialty in family/general medicine, internal medicine, obstetrics / gynecology, pediatrics, or emergency medicine was obtained from the MSMS and used as the sampling frame. These five specialties were selected because physicians in these specialties were perceived to be more likely to have contact with patients in need of ECP. A random sample of 170 physicians within each specialty was drawn from this mailing list using a random number generator, for an overall sample of 850 physicians in Michigan.

A self-administered questionnaire was developed by the investigators. Several questions were taken or adapted from the survey instrument 
used in the Kaiser Family Foundation's $2001 \mathrm{Na}$ tional Survey of Women's Health Care Providers on Reproductive Health. ${ }^{28}$ A preliminary version of the questionnaire was pilot-tested among a small group of physicians (including both attending physicians and residents) within the investigators' institution. Comments were elicited among these physicians regarding the clarity of survey questions and answer options. The questions and answer choices were accordingly modified, removed, or added. The final questionnaire contained 29 items assessing physicians' current practice regarding ECP provision, attitudes toward ECP provision, their demographics, and characteristics of their clinic/practice. Several questions were designed to allow for open-ended responses.

A survey packet containing the questionnaire, an individually addressed cover letter, and a postage-paid return envelope was mailed to the 850 physicians in July 2005. A postcard reminder was sent to all potential respondents 3 weeks after the first mailing. The survey was closed in October 2005. This study was approved by the University of Michigan Medical School Institutional Review Board.

Of the 850 surveys sent out, 10 were returned as undeliverable mails. A total of 271 physicians replied to the survey (response rate $=32 \%$ ). Of these respondents, 19 stated that the topic was not applicable to them and, hence, did not complete the questionnaire. Thus, data analyses were conducted on a final study population of 252 physicians.

\section{Statistical analyses}

Descriptive statistics were calculated to characterize respondents' demographics and features of their clinic/practice. Differences in physicians' attitudes and practices regarding ECP provision by demographic and clinical characteristics were assessed using chi-square tests. For attitudes toward OTC provision of ECP, the responses were categorized as Yes, No, or Neutral/don't know. For practices surrounding advance prescription, the answers were dichotomized to Ever (i.e., Always/Most of the time/Sometimes) vs. Never. Because of the small sample size, most of the demographic and clinical characteristics were dichotomized based on their practical meaning (e.g., private practice vs. other types of practice) or to generate two similar-sized groups (e.g., year of graduation from medical school on or before 1990 vs. after 1990).

We also performed ordered and binary multivariable logistic regression analyses to examine two outcome variables measuring physicians' approval of the OTC status of ECP (among physicians in all five specialties) and their practice of advance provision of ECP (excluding physicians in emergency medicine), respectively. Physicians' demographic and clinical characteristics ascertained in the survey and factors that were found in previous studies to influence physicians' ECPrelated attitudes or practices (e.g., gender, specialty, and patient population $)^{29-31}$ were considered as potential explanatory variables. The final model included only variables that were shown to be significant in univariate analyses and physician gender, which we believed to be important in determining a physician's attitudes and practices regarding ECP. $p$ values $<0.05$ were considered statistically significant, and $p$ values between 0.05 and 0.10 were viewed as being marginally significant. All data analyses were performed using SAS 9.1 (SAS Institute, Cary, NC).

\section{RESULTS}

Demographic and clinic/practice characteristics of the 252 physicians in the final study population are summarized in Table 1. Most respondents were male and Caucasian, with a median age of 47 years. More than half of the physicians (57\%) reported that their patients were predominantly in the age range 18-55 years and were either primarily female or male and female. Compared with data from a recent survey of licensed Michigan physicians, ${ }^{24}$ most characteristics of the respondents in our survey are comparable to the general Michigan physician population except that our sample had lower proportions of Asian/Pacific Islander physicians and physicians who graduated from a medical school in a foreign country.

Overall, $42 \%$ of respondents favored OTC provision of ECP, and 40\% opposed it (Table 2). Physicians aged $\geq 50$ were more likely than their younger peers to approve dispensing ECP through this route. Likewise, physicians who graduated from a medical school on or before 1990 were more likely to favor OTC provision of ECP than physicians who completed their med- 
Table 1. Characteristics of Survey Respondents $(N=252)^{\mathrm{a}}$

\begin{tabular}{|c|c|c|}
\hline Characteristic & $\mathrm{n}$ & $\%$ of total \\
\hline Age, years, median (interquartile range) & $47(39-55)$ & - \\
\hline \multicolumn{3}{|l|}{ Gender } \\
\hline Male & 169 & 67.9 \\
\hline Female & 80 & 32.1 \\
\hline \multicolumn{3}{|l|}{ Race } \\
\hline White/Caucasian & 196 & 79.7 \\
\hline Black/African American & 14 & 5.7 \\
\hline Asian/Pacific Islander & 18 & 7.3 \\
\hline Other/multiple & 18 & 7.3 \\
\hline \multicolumn{3}{|l|}{ Latino/Hispanic ethnicity } \\
\hline Yes & 11 & 4.5 \\
\hline No & 233 & 95.5 \\
\hline \multicolumn{3}{|c|}{$\begin{array}{l}\text { Graduation from medical school within the United States } \\
\text { (including Puerto Rico) }\end{array}$} \\
\hline Yes & 210 & 84.7 \\
\hline No & 38 & 15.3 \\
\hline \multicolumn{3}{|l|}{ Year of graduation from medical school } \\
\hline 1970 or earlier & 9 & 3.6 \\
\hline $1971-1980$ & 53 & 21.3 \\
\hline 1981-1990 & 76 & 30.5 \\
\hline 1991-2000 & 82 & 32.9 \\
\hline After 2000 & 29 & 11.7 \\
\hline \multicolumn{3}{|l|}{ Type of practice } \\
\hline Private practice & 143 & 57.7 \\
\hline Other types of practice ${ }^{b}$ & 105 & 42.3 \\
\hline \multicolumn{3}{|l|}{ Salaried physician } \\
\hline Yes & 123 & 50.0 \\
\hline No & 123 & 50.0 \\
\hline \multicolumn{3}{|l|}{ Practice location } \\
\hline Urban & 88 & 36.5 \\
\hline Suburban & 100 & 41.5 \\
\hline Rural & 53 & 22.0 \\
\hline \multicolumn{3}{|c|}{ Number of hours per week spent on direct patient care } \\
\hline $0-20$ & 26 & 10.6 \\
\hline $21-40$ & 107 & 43.5 \\
\hline $41-60$ & 77 & 31.3 \\
\hline $61-80$ & 19 & 7.7 \\
\hline$>80$ & 17 & 6.9 \\
\hline
\end{tabular}

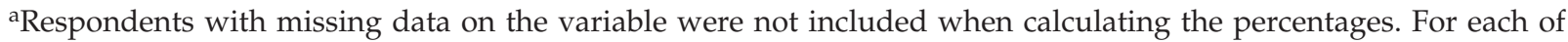
these variables, $<5 \%$ of the respondents had missing data.

bIncluding group/staff model HMO, teaching/academic hospital, community hospital (not university affiliated), public clinic, or other specified types of practice.

ical school education after 1990. Obstetrician/ gynecologists were most likely to say Yes when asked whether they thought ECP should be available OTC without a prescription, whereas family/general medicine physicians were the least likely to say so. In addition, physicians in private practice were less likely to favor OTC provision of ECP compared with physicians in other practicing settings (e.g., hospital employment). There were no significant differences in respondents' approval of OTC status of ECP by gender, race, practice location, or patient population.
In terms of current practices of emergency contraception provision, older physicians were more likely to offer their patients advance prescriptions of ECP. Compared with physicians in other specialties, obstetrician/gynecologists tended to offer an advance prescription of ECP more frequently. As expected, patient population affected physicians' practices regarding ECP provision. Those seeing more reproductive-age female patients were more likely to offer advance prescriptions.

Table 3 shows the association between physician characteristics and their ECP-related atti- 
Table 2. Differences in Attitudes and Practice Regarding

Emergency Contraception by Physician Characteristics ${ }^{a}$

\begin{tabular}{|c|c|c|c|c|c|c|c|}
\hline \multirow[b]{2}{*}{ Attitudes and practices } & \multicolumn{4}{|c|}{$\begin{array}{l}\text { Approval of OTC } \\
\text { status of } E C P^{\mathrm{b}}\end{array}$} & \multicolumn{3}{|c|}{$\begin{array}{c}\text { Offer of advance } \\
\text { prescription for ECPc }\end{array}$} \\
\hline & $\begin{array}{l}\text { Yes } \\
\%\end{array}$ & $\begin{array}{c}\text { Neutral/ } \\
\text { don't know } \\
\%\end{array}$ & $\begin{array}{l}\text { No } \\
\%\end{array}$ & $\mathrm{p}$ value & $\begin{array}{c}\text { Ever } \\
\%\end{array}$ & $\begin{array}{c}\text { Never } \\
\%\end{array}$ & $\mathrm{p}$ value \\
\hline Overall & 42.2 & 17.7 & 40.2 & - & 23.1 & 76.9 & - \\
\hline Age, years & & & & $<0.01$ & & & 0.05 \\
\hline$\geq 50$ & 56.6 & 18.9 & 24.5 & & 30.7 & 69.3 & \\
\hline$<50$ & 31.6 & 16.2 & 52.2 & & 18.3 & 81.7 & \\
\hline Gender & & & & 0.70 & & & 0.19 \\
\hline Male & 44.0 & 17.5 & 38.6 & & 19.8 & 80.2 & \\
\hline Female & 38.8 & 17.5 & 43.8 & & 28.4 & 71.6 & \\
\hline Race & & & & 0.997 & & & 0.99 \\
\hline White/Caucasian & 42.5 & 17.6 & 39.9 & & 23.4 & 76.6 & \\
\hline Nonwhite/Caucasian & 42.0 & 18.0 & 40.0 & & 23.3 & 76.7 & \\
\hline Medical specialty & & & & 0.02 & & & $<0.01$ \\
\hline Family/general medicine & 30.9 & 18.2 & 50.9 & & 14.3 & 85.7 & \\
\hline Internal medicine & 48.4 & 6.5 & 45.2 & & 6.5 & 93.6 & \\
\hline Obstetrics/gynecology & 50.9 & 8.8 & 40.4 & & 42.1 & 57.9 & \\
\hline Pediatrics & 42.2 & 17.8 & 40.0 & & 21.4 & 78.6 & \\
\hline Emergency medicine & 41.0 & 31.2 & 27.9 & & - & - & \\
\hline Location of medical school & & & & 0.09 & & & 0.33 \\
\hline Within United States & 39.6 & 17.4 & 43.0 & & 21.6 & 78.4 & \\
\hline Outside United States & 58.0 & 15.8 & 26.3 & & 29.4 & 70.6 & \\
\hline Year of graduation from medical school & & & & 0.01 & & & 0.99 \\
\hline 1990 or earlier & 48.9 & 19.0 & 32.1 & & 22.9 & 77.1 & \\
\hline After 1990 & 33.9 & 15.6 & 50.5 & & 23.0 & 77.0 & \\
\hline Type of practice & & & & $<0.01$ & & & 0.72 \\
\hline Private practice & 39.7 & 12.1 & 48.2 & & 21.9 & 78.1 & \\
\hline Hospital or other practice & 45.2 & 24.0 & 30.8 & & 24.4 & 75.6 & \\
\hline Practice location & & & & 0.47 & & & 0.72 \\
\hline Urban & 40.2 & 20.7 & 39.1 & & 20.4 & 79.6 & \\
\hline Suburban/rural & 42.4 & 14.6 & 43.1 & & 22.9 & 77.1 & \\
\hline Predominant patient population & & & & 0.53 & & & 0.05 \\
\hline $\begin{array}{l}\text { Age 18-55 and female or } \\
\text { both male and female }\end{array}$ & 41.4 & 15.0 & 43.6 & & 27.8 & 72.2 & \\
\hline Other patient population & 41.4 & 20.2 & 38.4 & & 15.5 & 84.5 & \\
\hline
\end{tabular}

aRespondents with missing data were not included in these statistics. For each of these statistics, $<8 \%$ of the respondents had missing data.

bThis variable was defined based on the survey question: Do you feel that emergency contraception should be available over-the-counter, without a prescription?

'This variable was defined based on the survey question: How often do you routinely offer your patients an advance prescription for emergency contraception? Ever represents the combined category of Always, Most of the time, and Sometimes (vs. Never). Physicians in emergency medicine were not included in this analysis.

tudes and practices based on the multivariable logistic regression analysis. Physicians aged $\geq 50$ were 2.9 times (95\% confidence interval [CI]) 1.74.9) as likely as their younger counterparts to have more favorable attitudes toward OTC provision of ECP and to have ever offered an advance prescription for ECP. Those who graduated from a medical school outside of the United States or who were not in private practice were also more likely to approve the OTC status of ECP.
Obstetrician/gynecologists were shown to be more likely than family/general medicine physicians to have ever offered advance provision of ECP. Although not a significant factor in univariate analysis, female gender was shown to be positively associated with a physician's likelihood of offering advance prescriptions for ECP (adjusted OR $=2.5,95 \%$ CI 1.05-6.0). After adjusting for other factors, a predominantly 18-55year-old female or male and female patient pop- 
Table 3. Logistic Regressions for Physicians' Attitudes and Practices Regarding the Provision of Emergency Contraceptive Pills

\begin{tabular}{|c|c|c|}
\hline Attitudes and practices & $\begin{array}{l}\text { Approval of } \\
\text { OTC status of ECPa } \\
\text { OR }(95 \% C I)^{\mathrm{c}}\end{array}$ & $\begin{array}{c}\text { Offer of advance } \\
\text { prescription for ECPb } \\
\text { OR }(95 \% \mathrm{CI})\end{array}$ \\
\hline Age $\geq 50($ vs. $<50)$ years & $2.9(1.7-4.9)^{* *}$ & $2.5(1.1-5.8)^{* *}$ \\
\hline Female (vs. male) & $1.1(0.6-1.9)$ & $2.5(1.05-6.0)^{* *}$ \\
\hline \multicolumn{3}{|l|}{ Medical specialty (reference category: family/general medicine) } \\
\hline Internal medicine & $1.3(0.5-3.1)$ & $0.2(0.02-2.0)$ \\
\hline Obstetrics/gynecology & $1.7(0.8-3.6)$ & $3.5(1.3-9.8)^{* *}$ \\
\hline Pediatrics & $1.2(0.5-2.8)$ & $1.2(0.3-4.9)$ \\
\hline Emergency medicine & $1.3(0.5-3.0)$ & - \\
\hline Medical school within United States (vs. outside United States) & $0.5(0.2-1.0)^{*}$ & - \\
\hline Private practice (vs. other types of practice) & $0.6(0.3-1.1)^{*}$ & - \\
\hline $\begin{array}{l}\text { Predominant patient population: aged } 18-55 \text { and } \\
\text { primarily female/male and female (vs. other } \\
\text { patient population) }\end{array}$ & - & $1.01(0.3-3.8)$ \\
\hline Sample sized & 239 & 176 \\
\hline $\operatorname{Pr}>$ chi-square & $<0.01$ & $<0.01$ \\
\hline
\end{tabular}

${ }^{*} p<0.10 ;{ }^{* *} p<0.05$.

a Outcome variable was defined based on the survey question: Do you feel that emergency contraception should be available over-the-counter, without a prescription? The model estimated the likelihood of more favorable attitudes toward the OTC status of ECP.

${ }^{b}$ Outcome variable was defined based on the survey question: How often do you routinely offer your patients an advance prescription for emergency contraception? The model estimated the likelihood of Ever vs. Never, where Ever represented the combined category of Always, Most of the time, and Sometimes. Physicians in emergency medicine were not included in this analysis.

'OR, odds ratio; $\mathrm{CI}$, confidence interval.

d Respondents who answered Not applicable to the question or with missing data were not included in the analysis (5.2\% and $7.4 \%$ of the respondents for the two regressions, respectively).

ulation was no longer a significant factor for advance prescriptions of ECP. Likewise, in univariate analyses, specialties in obstetrics/gynecology or emergency medicine (as opposed to family/ general medicine) were found to be positively associated with a physician's approval of OTC status, but such effects lacked statistical significance in multivariate analyses.

When asked about steps taken to promote patients' access to ECP, nearly half of the respondents $(48 \%)$ answered None (Table 4). Among those who did make a special effort to encourage access, prescribing ECP by telephone without the need for an office visit and making office staff aware of ECP availability in the clinic were most frequently reported. Of the $12 \%$ who reported Other actions to encourage access, about half said they provided relevant information to patients at various occasions, for example, "When asked" or "When situation arises" (data not shown).

Approximately half of the respondents had ever initiated a discussion about emergency contraception with their sexually active female patients. These physicians most frequently talked with patients about the timing and availability of emergency contraception, its effectiveness and side effects, as well as the various options of emergency contraception. Ninety five percent of these physicians recommended to their patients that they take the pills within 120 hours after unprotected sexual intercourse, and $66 \%$ always or most of the time clarified that it does not interrupt an established pregnancy (data not shown).

Respondents who were not emergency medicine physicians and did not always provide advance prescriptions for emergency contraception were asked about the reasons for not doing so. They most frequently $(75 \%)$ cited a lack of demand from patients as the reason. Some respondents (although a small proportion) expressed concern that they did not have sufficient knowledge about ECP. Of those who answered Other reasons, $16 \%$ said that advance provision of ECP was not appropriate for their patient population or their scope of care, as they were practicing in psychiatry/cardiology or mainly serving elderly or pregnant patients (data not shown). 
Table 4. Other Practices and Attitudes Regarding Emergency Contraception Provision ${ }^{\mathrm{a}}$

\begin{tabular}{|c|c|c|}
\hline Other practices and attitudes & $\mathrm{n}$ & $\%$ \\
\hline \multicolumn{3}{|l|}{ What steps, if any, do you take to encourage access to emergency contraception? ${ }^{\mathrm{b}}$} \\
\hline Making information on emergency contraception visible in your clinic & 39 & 16.1 \\
\hline $\begin{array}{l}\text { Prescribing emergency contraception by telephone without the need } \\
\text { for an office visit }\end{array}$ & 76 & 31.4 \\
\hline Prescribing/dispensing emergency contraception to potential users in advance & 24 & 9.9 \\
\hline Making all office staff aware that emergency contraception is provided in your clinic & 53 & 21.9 \\
\hline Other & 29 & 12.0 \\
\hline None & 117 & 48.4 \\
\hline \multicolumn{3}{|l|}{$\begin{array}{l}\text { How often do you routinely initiate discussion about emergency contraception with } \\
\text { your sexually active female patients? }\end{array}$} \\
\hline Always & 11 & 4.4 \\
\hline Most of the time & 20 & 8.0 \\
\hline Sometimes & 93 & 37.1 \\
\hline Never & 127 & 50.6 \\
\hline \multicolumn{3}{|l|}{ What aspects of emergency contraception do you routinely discuss with your patients? ${ }^{b, c}$} \\
\hline Various options (such as copper-T IUD, Plan-B ${ }^{\circledR}$, birth control pills) & 65 & 52.4 \\
\hline Availability & 85 & 68.6 \\
\hline Effectiveness & 90 & 72.6 \\
\hline Safety & 60 & 48.4 \\
\hline Mechanism (such as the inhibition of ovulation, fertilization, or implantation) & 45 & 36.3 \\
\hline Timing & 90 & 72.6 \\
\hline Side effects & 69 & 55.7 \\
\hline \multicolumn{3}{|l|}{$\begin{array}{l}\text { What are the reasons why you do not always routinely provide prescriptions for } \\
\text { emergency contraception? }{ }^{\mathrm{b}, \mathrm{d}}\end{array}$} \\
\hline Not much demand from pataients & 134 & 75.3 \\
\hline Concerns about safety or efficacy & 9 & 5.1 \\
\hline $\begin{array}{l}\text { Personally oppose the use of emergency contraception (such as for religious } \\
\text { or moral reasons) }\end{array}$ & 21 & 11.8 \\
\hline Emergency contraception use may promote promiscuity & 10 & 5.6 \\
\hline Emergency contraception use may discourage regular contraceptive use & 31 & 17.4 \\
\hline Medical liability concerns & 10 & 5.6 \\
\hline Do not know enough about emergency contraception & 16 & 9.0 \\
\hline Other & 44 & 24.7 \\
\hline
\end{tabular}

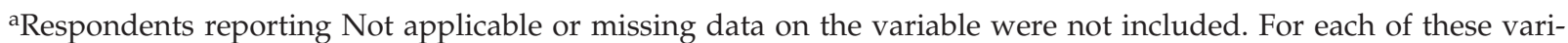
ables, $<5 \%$ of the respondents had missing data.

bPercentages added to $>100 \%$ because respondents could choose multiple options.

${ }^{c}$ Among 124 respondents reporting ever initiated discussion about emergency contraception with their sexually active female patients.

dAmong 187 respondents who were not in emergency medicine and reported not always providing advance prescriptions for ECP.

\section{DISCUSSION}

Timely access to ECP is a critical component of its efficacy and has the potential to prevent many unintended pregnancies. The current study examined ECP-related attitudes and practices in a broad group of physicians in Michigan (from five medical specialties perceived as more likely to encounter patients in need of ECP). Similar to other surveys, ${ }^{28}$ we observed divided attitudes among physicians about OTC provision of ECP even though a number of health professional organizations, including the American Medical Association, the American Public Health Association, the American College of Obstetricians and Gynecologists, the American Academy of Pediatrics, the American College of Emergency Physicians, and at least 60 other organizations, support increasing access through this route. ${ }^{3,32-34}$ Fortytwo percent of survey respondents favored OTC provision of ECP, whereas $40 \%$ opposed it.

These attitudes were not associated with physician characteristics other than age, graduation from a medical school outside the United States, and type of practice. Few studies have examined physicians' attitudes toward ECP provision by physician characteristics. Golden et al. $^{35}$ found that although younger pediatricians were more 
likely than older pediatricians to have been confronted with the decision to prescribe ECP, there were no differences in their comfort level about prescribing ECP. Our study, however, indicates that older physicians were significantly more likely than younger physicians to support OTC provision of ECP or offer advance prescriptions to patients. This finding was unexpected. It is likely that because older physicians have seen more patients and have more personal experience than younger physicians, they are more cognizant and empathic about unintended pregnancies and their impact on patients' lives. The exact reasons, however, warrant further research.

The majority of respondents (77\%) in our study (not including physicians in emergency medicine) had never offered an advance prescription of ECP to their patients. Comments from physicians about why they did not routinely provide advance prescriptions of ECP underscore certain aspects of practice that may hinder timely access to ECP and, at the same time, highlight opportunities for physicians to increase patients' access.

Overall, barriers to advance provision of ECP identified in our study are consistent with those suggested by other studies. $7,18,28,35-38$ Few concerns about the safety and efficacy of taking ECP were raised by physicians. Rather, some respondents worried that use of ECP may discourage regular contraceptive use $(17 \%)$ or encourage promiscuity $(6 \%)$. Other studies have found similar concerns among physicians, 7,18,38 although such concerns may be unfounded. ${ }^{39}$ It has been shown that compared to clinic access, increased access to ECP via direct pharmacy access or advance provision helps increase ECP use among those in need and allows patients to use it in a more timely manner without changing women's patterns of contraceptive use or sexual risk behaviors. ${ }^{9,40-42}$ Research from UK also demonstrates that allowing OTC provision of ECP does not reduce the use of regular contraceptives. ${ }^{14}$

Additionally, $12 \%$ respondents said they personally opposed the use of ECP and, hence, did not provide advance prescription. Prior research has observed differences in providers' willingness to offer ECP after sexual assault and consensual sex, indicating that providers' personal ethnical or religious beliefs played a role in offering ECP. ${ }^{31}$ The reasons for personal opposition to ECP use were not directly queried in our survey, but other studies have shown a correlation between such opposition and the belief that ECP acts as an abortifacient. ${ }^{7,18,43}$ However, research shows that ECP does not interfere with an established pregnancy ${ }^{2}$ and is unlikely to affect an egg once it has been fertilized even if taken before implantation. ${ }^{44}$ These concerns about interference with regular contraceptive use and as a cause of promiscuity and abortion are likely important reasons for some physicians' opposition to the OTC status of ECP as well.

Seventy-five percent of respondents reported they did not provide ECP in advance because of a lack of demand among patients. Other respondents commented that "No one has asked" or that patients could easily contact them by phone or pager. This does not preclude the need for advance prescription of $\mathrm{ECP}$, however, as patients may not feel comfortable asking for ECP or they may not be aware of the availability of ECP or how to access it. Physicians may need to reassess how they determine a patient's need for ECP. The literature on urinary incontinence and erectile dysfunction suggests that even if treatment is desired, many patients are reluctant to initiate certain subjects and would prefer their physicians to initiate the subject. ${ }^{4,46}$ Likewise, discomfort about topics related to sexuality or birth control may inhibit patients from broaching the issue. ${ }^{47}$ An assumption that there is no need unless the patients introduce the topic may result in missed opportunities to both inform women about ECP and provide the medication.

Physician education regarding the mechanism of emergency contraception and steps that can be taken to improve women's timely access to ECP may be beneficial. Indeed, prior studies have suggested that physicians' knowledge deficits about ECP are associated with low provision rates ${ }^{37}$ and that educational interventions among providers help increase their initiation of ECP discussion with patients ${ }^{48}$ and the frequency of ECP prescription. ${ }^{21}$ In the meantime, education to help patients overcome the discomfort of initiating ECP-related discussions with providers may be equally important. In this aspect, the American College of Obstetricians and Gynecologists has set an example by recently launching a campaign called "Ask Me," which emphasizes educating women about emergency contraception and encourages sexually active women to obtain an advance prescription for emergency contraception from their physicians. ${ }^{49}$

Several limitations of the study should be acknowledged. First, the survey had a relatively 
low response rate. As noted in the Results section, most demographic characteristics of the respondents were comparable to the overall physician population in Michigan. The impact of nonresponse bias by physician demographics is likely small. However, it is possible that responding physicians had more favorable attitudes than nonrespondents toward ECP. Second, in-depth information about each respondent's patient population was not available. Some of the differences in ECP provision practices across specialties may be due to inherent differences in the patient population or the physician's scope of practice. Third, the survey was conducted among physicians within Michigan. Their attitudes and practices may not be broadly generalizable to physicians elsewhere in the country.

\section{CONCLUSIONS}

Even though the FDA recently approved the sale of ECP without a prescription to men and women aged $\geq 18,{ }^{16}$ physicians still play an important role in educating women about ECP and its optimal use and in serving as a primary provider of ECP for women under the age of 18. Findings from this study suggest that there are multiple opportunities to optimize women's access to and use of ECP. There may be a need to address physicians' concerns and attitudes about ECP through education, particularly those aspects that may create barriers to care and influence current practices of advance provision. Interventions aimed at patient education and improving patient-provider communication may also help enhance women's timely access to ECP.

\section{ACKNOWLEDGMENT}

We thank Neel K. Agrawal for excellent assistance with survey implementation.

\section{REFERENCES}

1. Jones RK, Darroch JE, Henshaw SK. Contraceptive use among U.S. women having abortions in 2000-2001. Perspect Sex Reprod Health 2002;34:294.

2. Trussell J, Ellertson C, Stewart F, Raymond EG, Shochet T. The role of emergency contraception. Am I Obstet Gynecol 2004;190:S30.
3. Ranney ML, Gee EM, Merchant RC. Nonprescription availability of emergency contraception in the United States: Current status, controversies, and impact on emergency medicine practice. Ann Emerg Med 2006;47:461.

4. U.S. Food and Drug Administration. Prescription drug products: Certain combined oral contraceptives for use as postcoital emergency contraception. Fed Register 1997;62:8610.

5. Wertheimer RE. Emergency postcoital contraception. Am Fam Physician 2000;62:2287.

6. Gardner JS, Hutchings J, Fuller TS, Downing D. Increasing access to emergency contraception through community pharmacies: Lessons from Washington State. Fam Plann Perspect 2001;33:172.

7. Kumar AS, Hall LC, LePage A, Lim PC. Providing emergency contraceptive pills "behind-the-counter": Opinions among Minnesota healthcare providers. Contraception 2003;68:253.

8. Hellerstedt WL, Van Riper KK. Emergency contraceptive pills: Dispensing practices, knowledge and attitudes of South Dakota pharmacists. Perspect Sex Reprod Health 2005;37:19.

9. Gold MA, Wolford JE, Smith KA, Parker AM. The effects of advance provision of emergency contraception on adolescent women's sexual and contraceptive behaviors. J Pediatr Adolesc Gynecol 2004;17:87.

10. Belzer M, Yoshida E, Tejirian T, Tucker D, Chung K, Sanchez K. Advanced supply of emergency contraception for adolescent mothers increased utilization without reducing condom or primary contraception use. I Adolesc Health 2003;32:122.

11. Blanchard K, Bungay H, Furedi A, Sanders L. Evaluation of an emergency contraception advance provision service. Contraception 2003;67:343.

12. Ellertson C, Ambardekar S, Hedley A, Coyaji K, Trussell J, Blanchard K. Emergency contraception: Randomized comparison of advance provision and information only. Obstet Gynecol 2001;98:570.

13. Raine T, Harper C, Leon K, Darney P. Emergency contraception: Advance provision in a young, high-risk clinic population. Obstet Gynecol 2000;96:1.

14. Marston C, Meltzer H, Majeed A. Impact on contraceptive practice of making emergency hormonal contraception available over the counter in Great Britain: Repeated cross-sectional surveys. BMJ 2005;331:271.

15. Grimes DA, Raymond EG, Scott Jones B. Emergency contraception over-the-counter: The medical and legal imperatives. Obstet Gynecol 2001;98:151.

16. U.S. Food and Drug Administration. Plan B (0.75mg levonorgestrel) tablet information. Available at www.fda.gov/cder/drug/infopage/planB Accessed September 30, 2006.

17. Guttmacher Institute. Emergency contraception: State policies in brief. Available at www.guttmacher.org/ statecenter/spibs/spib_EC.pdfAccessed September 30, 2006.

18. Uzuner A, Unalan P, Akman M, et al. Providers' knowledge of, attitude to and practice of emergency contraception. Eur J Contracept Reprod Health Care 2005;10:43. 
19. Harrison T. Availability of emergency contraception: A survey of hospital emergency department staff. Ann Emerg Med 2005;46:105.

20. Rosenberg KD, Demunter JK, Liu J. Emergency contraception in emergency departments in Oregon, 2003. Am J Public Health 2005;95:1453.

21. Beckman LJ, Harvey SM, Sherman CA, Petitti DB. Changes in providers' views and practices about emergency contraception with education. Obstet Gynecol 2001;97:942.

22. Scholle SH, Chang JC, Harman J, McNeil M. Trends in women's health services by type of physician seen: Data from the 1985 and 1997-98 NAMCS. Womens Health Issues 2002;12:165.

23. Michigan State Medical Society. The future supply and demand for physicians in Michigan. Available at www.msms.org/bsyp/news/PhysicianShortageFull.pdf Accessed March 21, 2006.

24. Michigan Department of Community Health. Survey of physicians, 2005. Available at mhc.org/mhc_images/physiciansurvey2005.pdf Accessed February 27, 2006.

25. Michigan State Medical Society. A guide to membership. Available at www.msms.org/msmsto/aboutmsms/ wwd.html\#strength Accessed March 1, 2006.

26. Novak J. 2005 MSMS Physician data survey on practice characteristics. Mich Med 2005;104:8, 14.

27. Michigan State Medical Society. MDCH study mirrors MSMS findings on physician shortage. Available at www.msms.org/AM/Template.cfm?Section $=$ SearchE template $=/ C M / H T M L D i$ splay.cfmEContent $I D=1325$ Accessed September 30, 2006.

28. Kaiser Family Foundation. National survey of women's health care providers on reproductive health: Emergency contraception. Available at www.kff.org/ womenshealth/3346-index.cfm Accessed January 9, 2006.

29. Chuang CH, Waldman LJ, Freund KM, Ash AS. Emergency contraception: Prescribing practices of general internists compared with other primary care physicians. Contraception 2004;69:43.

30. Sills MR, Chamberlain JM, Teach SJ. The associations among pediatricians' knowledge, attitudes, and practices regarding emergency contraception. Pediatrics 2000;105:954.

31. Keshavarz R, Merchant RC, McGreal J. Emergency contraception provision: A survey of emergency department practitioners. Acad Emerg Med 2002; 9:69.

32. American Academy of Pediatrics. Policy statement: Emergency contraception. Pediatrics 2005;116:1026.

33. American College of Obstetricians and Gynecologists. ACOG practice bulletin, number 69: Emergency contraception. Obstet Gynecol 2005;106:1443.

34. American Medical Association. Access to emergency contraception. Available at www.ama-assn.org/ama/ pub/category/3565.html Accessed November 23, 2005.

35. Golden NH, Seigel WM, Fisher M, et al. Emergency contraception: Pediatricians' knowledge, attitudes, and opinions. Pediatrics 2001;107:287.
36. Karasz A, Kirchen NT, Gold M. The visit before the morning after: Barriers to preprescribing emergency contraception. Ann Fam Med 2004;2:345.

37. Wallace JL, $\mathrm{Wu}$ J, Weinstein J, Gorenflo DW, Fetters MD. Emergency contraception: Knowledge and attitudes of family medicine providers. Fam Med 2004;36:417.

38. Ziebland S, Graham A, McPherson A. Concerns and cautions about prescribing and deregulating emergency contraception: A qualitative study of GPs using telephone interviews. Fam Pract 1998;15:449.

39. Glasier A, Baird D. The effects of self-administering emergency contraception. N Engl J Med 1998;339:1.

40. Jackson RA, Schwarz EB, Freedman L, Darney P. Advance supply of emergency contraception. Effect on use and usual contraception-A randomized trial. Obstet Gynecol 2003;102:8.

41. Raine TR, Harper CC, Rocca CH, et al. Direct access to emergency contraception through pharmacies and effect on unintended pregnancy and STIs: A randomized controlled trial. JAMA 2005;293:54.

42. Harper CC, Cheong M, Rocca CH, Darney PD, Raine TR. The effect of increased access to emergency contraception among young adolescents. Obstet Gynecol 2005;106:483.

43. Sherman CA, Harvey SM, Beckman LJ, Petitti DB. Emergency contraception: Knowledge and attitudes of health care providers in a health maintenance organization. Womens Health Issues 2001;11:448.

44. Trussell J, Ellertson C, Dorflinger L. Effectiveness of the Yuzpe regimen of emergency contraception by cycle day of intercourse: Implications for mechanism of action. Contraception 2003;67:167.

45. Giuliano FA, Leriche A, Jaudinot EO, de Gendre AS. Prevalence of erectile dysfunction among 7689 patients with diabetes or hypertension, or both. Urology 2004;64:1196.

46. Newman DK. Report of a mail survey of women with bladder control disorders. Urol Nurs 2004;24:499.

47. Delbanco TL, Daley J. Through the patient's eyes: Strategies toward more successful contraception. $\mathrm{Ob}-$ stet Gynecol 1996;88:41S.

48. Chuang $\mathrm{CH}$, Freund KM. Emergency contraception: An intervention on primary care providers. Contraception 2005;72:182.

49. American College of Obstetricians and Gynecologists. ACOG steps up efforts to get emergency contraception to women. Available at wwww.acog.org/from_home/ publications/press_releases/nr05-08-06-1.cfm Accessed May 31, 2006.

Address reprint requests to: Xiao Xu, Ph.D. Department of Obstetrics and Gynecology University of Michigan L4000 Women's Hospital 1500 E. Medical Center Drive Ann Arbor, MI 48109

E-mail: xiaox@med.umich.edu 